\title{
Comparison of low frequency signals emitted by wind turbines of two different generator types
}

\author{
Tomasz Malec ${ }^{1}$, Tomasz Boczar ${ }^{2, *}$, Daria Wotzka $^{2}$, and Pawet Frącz ${ }^{2}$ \\ ${ }^{1}$ KFB Polska Spółka z o.o., ul. Mydlana 7, 51-502 Wrocław, Poland \\ ${ }^{2}$ Opole University of Technology, ul. Prószkowska 76, 45-758 Opole, Poland
}

\begin{abstract}
Paper presents results of comparative analysis of infrasound noise generated by wind turbines of two types: asynchronous type REPOWER MM92 with power equal to 2 MW and synchronous type Vensys 62 with power equal to 1.2 MW. Frequency spectra of sound pressure levels generated during operation by both turbines for exemplary chosen wind speed values are depicted. Within the shown spectra the resonant frequencies have been indicated, for which sound pressure variations over time are shown. Based on the achieved frequency spectra it was stated that in general the asynchronous type turbine produces lower pressure levels, which are less stable over time, and indicates higher pressure values around the resonant frequencies as compared to the synchronous type turbine. Also it was stated that the asynchronous type turbine is more influenced by the wind conditions and generates higher pressure values by higher wind speeds then the synchronous type turbine. The main contribution of this paper lies in indication that the type of wind turbine generator has significant impact on the level of infrasound noise emitted to the environment.
\end{abstract}

\section{Introduction}

The problem of formation, propagation, level and possible impact of infrasound, generated by artificial sources on the natural environment and especially on living organisms, is still valid and important [1]. This is particularly true for wind power engineering, which infrastructure is dynamically developing in recent years in the world. The possibility of measurement and understanding the phenomena related to generation and propagation of low-frequency acoustic signals can contribute to determine the impact of sound pressure levels, emitted by wind turbines with set parameters, on the natural environment. The results obtained due to experimental tests and measurements on real units can be referenced to the maximum allowable infrasound noise levels, which are defined in the standards related to the working environment (Regulation of the Minister of Labor and Social Policy 2002 on the maximum allowable concentrations and intensities of harmful factors at work). Infrasound noise generated by modern high-power wind turbines is a problem frequently raised for opinions on their impact on the environment. There exist a large number of publications relating to the measurement, analysis and computer modeling of infrasound emitted by wind turbines. To mention a few, but far not all: [2-12]. Experimental setups for measuring of infrasound are described among others in [13-14], where authors describe a digital data acquisition system that can be used to record signals from infrasound events. Methods for technical condition monitoring and diagnosis are presented e.g. in [15-18]. If interested in other studies regarding generation of noise and vibration caused by electric power devices the reader is referenced to e.g. [20-21].

In contrast, none of the publicly available work applies to the analysis of the impact of the type of generator on the results obtained. The main cognitive purpose of the research works performed by our team is to investigate the phenomenon of formation and propagation of low frequency acoustic waves emitted due to wind turbine operation. The performed research focuses on determining the impact of e.g.: construction solutions, power capacity, atmospheric conditions and wind speed on the values of basic parameters characterizing the emitted low-frequency noise and spatial distributions of the generated sound pressure. In previous studies vibrations of wind turbines of various power capacities as well as sound pressure levels of the emitted signals in the audible range have been measured. Preliminary measurements and analyses results of infrasound and vibrations generated by different kinds of turbines have been presented among others in [22-26].

The main objective of this paper was to present results of a comparative analysis aimed at determination of the infrasonic noise spectrum for different types of generators and at indication whether differences in the noise spectra are important and that should be considered when choosing the type of generator turbine. There exist a number of different types of turbines. A detailed characteristic of various configurations and design techniques is given among others in [27]. In this paper we examine two different constructions of wind turbines: type asynchronous and type synchronous, which differ

*Corresponding author: t.boczar@po.opole.pl 
according to the applied power generator and method of transferring the wind energy to the generator circuit. In the asynchronous unit, wind energy is transferred to the generator via transmission system, adjusting the rotor speed to the nominal speed of the generator. Synchronous units are not equipped with a transmission system. The whole energy generated by the rotor is directly transmitted to the generator, which has a large number of pole pairs, between which switching occurs depending on the number of rotations.

\section{Methodology and characteristics of the turbine under study}

For both types of constructions the low frequency measurements were performed basing on regulations of the PN-EN 61400-11 standard. The standard allows determination of the acoustic power level of wind turbine for different wind speeds (in practice, from 5 to $10 \mathrm{~m} / \mathrm{s}$ ) in a reproducible manner. Such measurements enable for determination of sound power level in the audible frequency range (from $50 \mathrm{~Hz}$ to $10000 \mathrm{~Hz}$ ) including tonality and directionality (optional). The standard precisely defines all requirements for the measuring equipment, measurement procedures, analysis methods of measurement results and the uncertainty analysis of the registered data. The standard also permits extension of the research on the infrasound range, but it does not define exactly how to measure it. The present study focuses on the measurement of the sound pressure level. This allows for identification of the range of potential impacts of infrasound at the measuring point location. Simultaneously to the measurement of sound level, the wind speed and direction, as well as other basic meteorological parameters were recorded in accordance with the standard (PN-EN 61400-11:2002 and 2004). The measurement was carried out through a continuous multi-hour measurement using sampling frequency equal to $51.2 \mathrm{kHz}$ (full registration with listening capability). Then, within the analysis of the recorded signal, the FFT analysis in the band up to $200 \mathrm{~Hz}$, with a resolution of 1 $\mathrm{Hz}$ (calculations made in LabShop B \& K) was performed. The readings of measured values were performed with a second sampling using the multibufor tool.

The subject of acoustic background was also considered and the disturbing events were observed and registered during the measurements. All identified interferences were excluded from the data set subjected for analyzes. It is to mention that for measurements a turbine located at the periphery of the farm was selected, taking into account the wind direction on a given measurement day (avoiding the presence of other turbines on the measuring axis of the turbinemicrophone). In addition, both turbines are located away from national roads and motorways. In order to avoid the risk of interference the measurements were performed in accordance to the requirements of EN 61400-11 standard, thus in the vicinity of the infrasound source. This allows achieving the highest accuracy in the ,in situ" assessment of typical wind farms under normal operation.

The objects under study were two wind turbines: the first with asynchronous and the second with synchronous generator of rated power equal to $2.0 \mathrm{MW}$ and $1.2 \mathrm{MW}$ respectively. The asynchronous turbine is part of a newly commissioned wind farm, consisting of 15 similar turbines with a total electrical power equal to $30 \mathrm{MW}$. This is a REPOWER wind turbine, type MM92, of electrical power equal to $2 \mathrm{MW}$. Diameter of the turbine blades equals $92 \mathrm{~m}$ and the tower height is $80 \mathrm{~m}$. The considered turbine is an outside standing turbine, thus the impact of infrasound noise, emitted by the other turbines, is minimized. The synchronous type turbine is a five years old Vensys device, type 62, with rated power equal to 1.2 MW. Diameter of the turbine blades is $62 \mathrm{~m}$ and the tower height is $69 \mathrm{~m}$. This turbine does not belong to a larger farm; however it is located in a neighborhood of other turbines. Nevertheless, also in this case the impact of low frequency noise, emitted by other turbines, is minimized.

The acoustic pressure levels were measured using a set from Brüel \& Kjær. This set consisted of a microphone, type 4190, designed for highly accurate measurements in free field, which was connected to LAN-XI 3050-A-060, a PULSE instrument. The registered frequencies were in the range from $1.2 \mathrm{~Hz}$ to $20 \mathrm{kHz}$, for which the transducer response is linear within $\pm 3 \mathrm{~dB}$. A double cover was used in accordance with PN-EN 61400-11:2002 and 2004 standard, For the noise data analysis, the frequency range was narrowed to infra and low frequencies, up to $100 \mathrm{~Hz}$. The applied Brüel \& Kjær LAN-XI instrument is equipped with specialized software, PULSE LabShop, which allows for pre-processing of the recorded data. For post-processing of the measured signals the MATLAB environment was applied.

Parallel to sound pressure level also the meteorological conditions were measured using a DAVIS weather station -the Vantage Pro2 Instrument. This device is equipped with a unit of integrated sensors, which record data that is further transmitted to a PC computer wirelessly: temperature was measured within the range from $-40{ }^{\circ} \mathrm{C}$ to $+65^{\circ} \mathrm{C}$, with accuracy equal to $+/-0.1{ }^{\circ} \mathrm{C}$, atmospheric pressure was measured in the range (810-1080) $\mathrm{hPa}$ with an accuracy of $+/-1 \mathrm{hPa}$, humidity was measured in the range from 0 to $100 \%$, with an accuracy of $3 \%$, air flow velocity was measured in the range (0-68) $\mathrm{m} / \mathrm{s}$, with an accuracy of $+/-0.2 \mathrm{~m} / \mathrm{s}$. A summary over meteorological parameters, occurring during measurements is presented in Table 1.

During tests the wind speed values fluctuated significantly in the range from $1.3 \mathrm{~m} / \mathrm{s}$ to $9.8 \mathrm{~m} / \mathrm{s}$, which allowed for performing analysis within a relatively wide range of wind speed impact on the infrasound level generated by the examined turbines. Other meteorological parameters and turbine operating conditions remained at a constant level and did not change significantly during the measurements. This article does not include results of uncertainty measurements. 
Table 1. Summary over the meteorological parameters, occurring during measurements (AT - asynchronous turbine, ST - synchronous turbine).

\begin{tabular}{|c|c|c|c|c|c|c|c|c|c|}
\hline \multicolumn{2}{|c|}{} & \multicolumn{3}{|c|}{ Maximal value } & \multicolumn{2}{c|}{ Minimal value } & \multicolumn{2}{c|}{ Mean value } & \multicolumn{2}{c|}{$\begin{array}{l}\text { Standard } \\
\text { deviation }\end{array}$} \\
\hline Parameter & Unit & AT & ST & AT & ST & AT & ST & AT & ST \\
\hline Temperature & ${ }^{\circ} \mathrm{C}$ & 24.8 & 5.9 & 17.1 & 5.1 & 21.2 & 5.6 & 2.3 & 0.3 \\
\hline Humidity & $\%$ & 71 & 79 & 44 & 75 & 56.5 & 77.5 & 7.5 & 1.0 \\
\hline Dew Point & ${ }^{\circ} \mathrm{C}$ & 13.2 & 2.3 & 11.2 & 1.6 & 12.0 & 2.0 & 0.4 & 0.2 \\
\hline Pressure & $\mathrm{hPa}$ & 1001.6 & 1021.9 & 1000.2 & 1021.2 & 1000.8 & 1021.5 & 0.4 & 0.1 \\
\hline Wind speed & $\mathrm{m} / \mathrm{s}$ & 7.6 & 9.8 & 1.3 & 3.6 & 4.8 & 6.2 & 1.4 & 1.2 \\
\hline Precipitation & $\mathrm{mm}$ & 0 & 0 & 0 & 0 & 0 & 0 & 0 & 0 \\
\hline
\end{tabular}

The measurements of low frequency noise generated by the considered turbines were performed with accordance to standard, in a single reference point at a distance equal to $100 \mathrm{~m}$ and $131 \mathrm{~m}$, respectively. The location of individual components of the measurement system in relation to the test turbine is presented in Figs. 1 and 2.

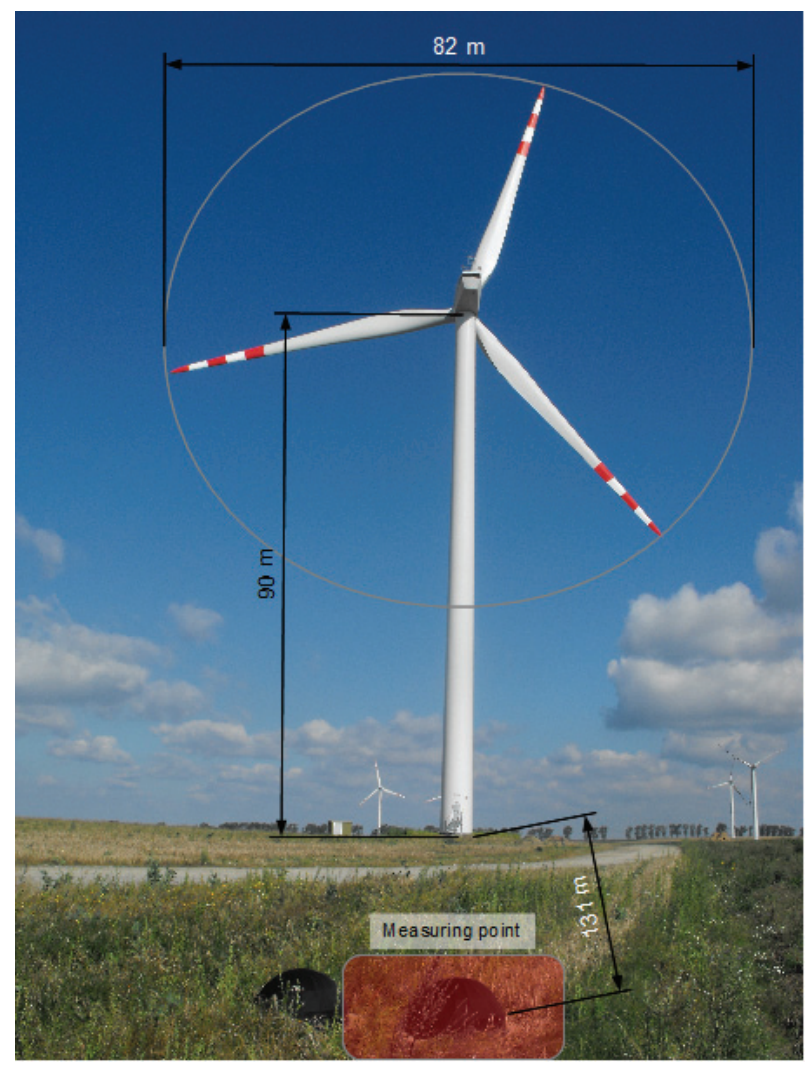

Fig. 1. Location of the infrasound noise level measuring point at the asynchronous type turbine.

\section{Results and discussion}

The scope of works, results of which are presented below, includes analyses of frequency spectra of sound pressure levels generated during operation by both considered turbine types. Regarded data apply to three characteristic values of wind speed: $5.4 \mathrm{~m} / \mathrm{s}, 6.3 \mathrm{~m} / \mathrm{s}$ and $7.6 \mathrm{~m} / \mathrm{s}$.

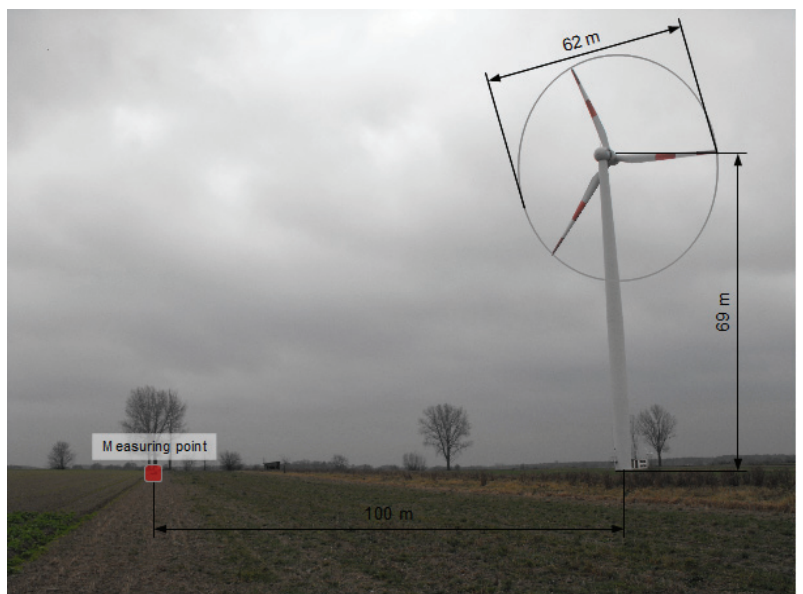

Fig. 2. Location of the infrasound noise level measuring point at the synchronous type turbine.

These values exemplify in a representative manner the range of significant changes in recorded signals. The lowest selected wind speed of $5.4 \mathrm{~m} / \mathrm{s}$ regards the impact on the turbine immediately after its start-up. The middle value of $6.3 \mathrm{~m} / \mathrm{s}$ affects the noise spectrum generated during turbine operation in the center of its energy efficiency. The highest measured wind speed value equal to $7.6 \mathrm{~m} / \mathrm{s}$ implies infrasound noise emission at the maximum turbine energy efficiency, per day.

In Figs. 3 and 4 frequency spectra of sound pressure levels generated by operating of synchronous and asynchronous type wind turbines, for the selected wind speed values: $5.4 \mathrm{~m} / \mathrm{s}, 6.3 \mathrm{~m} / \mathrm{s}$ and $7.6 \mathrm{~m} / \mathrm{s}$, are presented. In the case of asynchronous type turbine, an increase in wind speed value results in visible growth of the sound pressure level of the generated noise; this applies to the whole range of the considered frequencies.

The largest values of measured signals were observed in the infrasound band from $1 \mathrm{~Hz}$ to $10 \mathrm{~Hz}$. Several characteristic harmonic components can also be distinguished. The most significant is to be found in the range from 20 to $31 \mathrm{~Hz}$. Within this range we observe narrower picks for higher wind speeds and wider picks for lower wind speeds. Also, the pick location depends on the wind speed value and is placed for higher wind speeds by higher frequencies. 


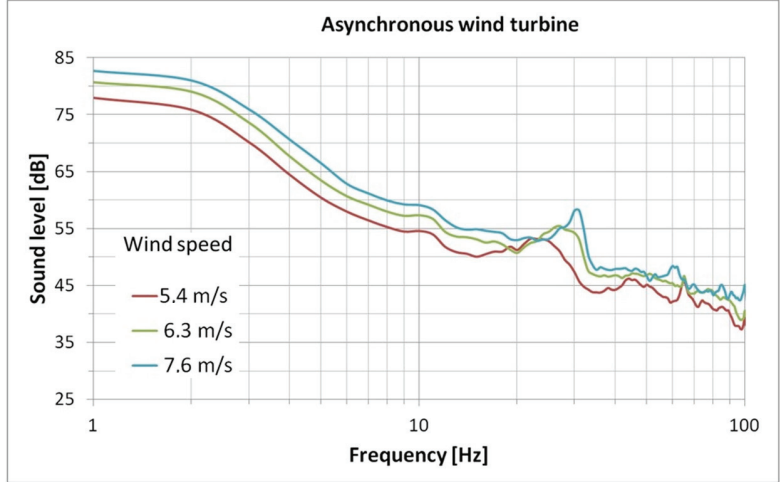

Fig. 3. Frequency spectra of sound pressure levels generated by operating asynchronous type wind turbine, for chosen wind speed values: $5.4,6.3$ and $7.6 \mathrm{~m} / \mathrm{s}$.

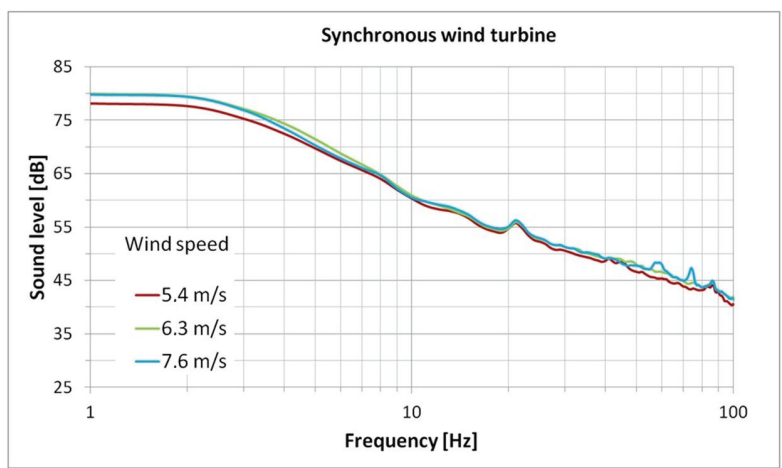

Fig. 4. Frequency spectra of sound pressure levels generated by operating synchronous type wind turbine, for chosen wind speed values: $5.4,6.3$ and $7.6 \mathrm{~m} / \mathrm{s}$.

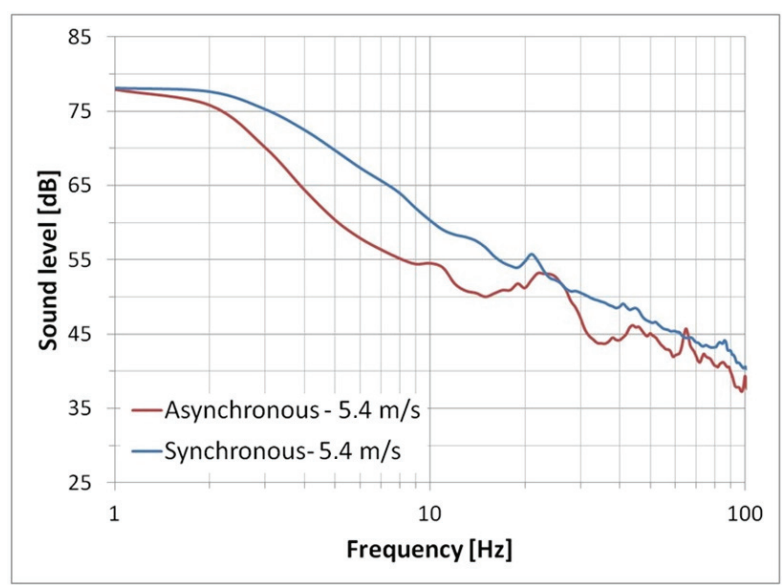

Fig. 5. Frequency spectra of sound pressure levels generated during normal operation of both turbines at wind speed value equal to $5.4 \mathrm{~m} / \mathrm{s}$; Pearson correlation coefficient $r=0.94$.

In the case of synchronous type turbine the wind speed value does not have so significant impact as it was for the other turbine type. In the frequency range up to $2.5 \mathrm{~Hz}$ there is no difference in the measured pressure levels for wind speeds above $6.3 \mathrm{~m} / \mathrm{s}$. Also the observed picks do not depict much higher sound pressure levels and achieve only several decibels more than it arises from the trend. All the harmonic components are found in the same frequency range independently of the wind speed.
In order to compare frequency spectra of the two considered turbine types with dependence to the wind speed, in Figures 5 and 6 appropriate characteristics are shown. For each dataset pair, the Pearson correlation coefficient $r$ was calculated. This indicator allows for qualitative assessment of correlations between the recorded signals.

Comparison of presented in Fig. 7 sound level spectra of both turbine types, calculated for signals generated at wind speed equal to $5.4 \mathrm{~m} / \mathrm{s}$, indicates major acoustic impact of the synchronous type turbine, values of which for the considered frequency range are higher than levels emitted by the asynchronous type turbine.

The calculated Pearson correlation coefficient between both signals amounts $r=0.94$ and indicates their strong linear correlation. Similar observations were done for data gathered at wind speed values equal to $6.3 \mathrm{~m} / \mathrm{s}$ (see Fig. 6) and $7.6 \mathrm{~m} / \mathrm{s}$ (see Fig. 7). Some significant differences are remarked in the frequency range up to about $2 \mathrm{~Hz}$, where by median wind speeds, the measured sound levels remain similar for both considered turbine types.

For the asynchronous type turbine, by wind speeds equal to $6.3 \mathrm{~m} / \mathrm{s}$, the measured sound levels are higher only within the harmonic frequencies range. The correlation of both signals is also strong and amounts $r$ $=0.94$.

During operation by highest wind speed values we observe that up to about $2.4 \mathrm{~Hz}$ the asynchronous type turbine generates higher sound levels then the synchronous type turbine.

In the range from $2.4 \mathrm{~Hz}$ to $45 \mathrm{~Hz}$, with except of the resonant frequencies, the synchronous type turbine generates higher sound levels. Above the frequency value equal to $45 \mathrm{~Hz}$ the depicted values remain very similar. The correlation of both signals is also strong and amounts $r=0.95$.

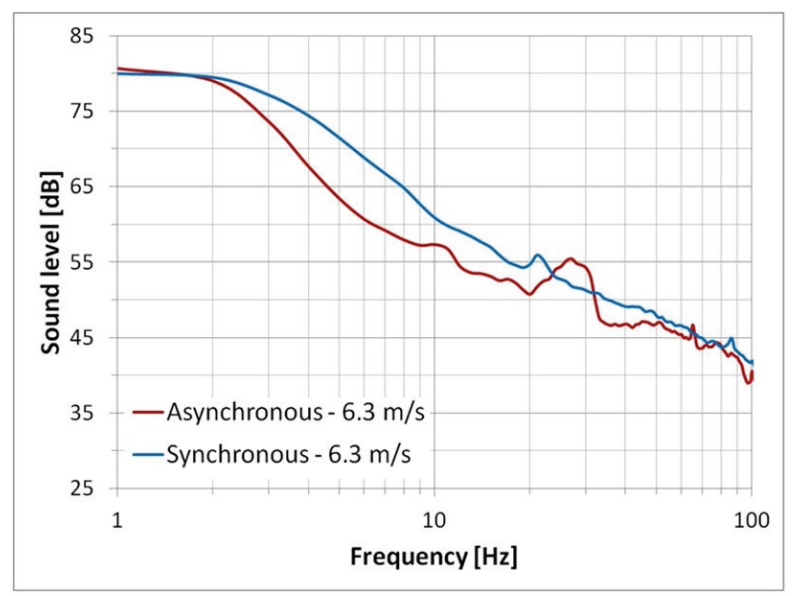

Fig. 6. Frequency spectra of sound pressure levels generated during normal operation of both turbines at wind speed value equal to $6.3 \mathrm{~m} / \mathrm{s}$; Pearson correlation coefficient $r=0.94$.

As already mentioned in the achieved spectra some resonant frequencies have been indicated. Indication of local maxima aims to demonstrate the tonal noise of wind turbines. 


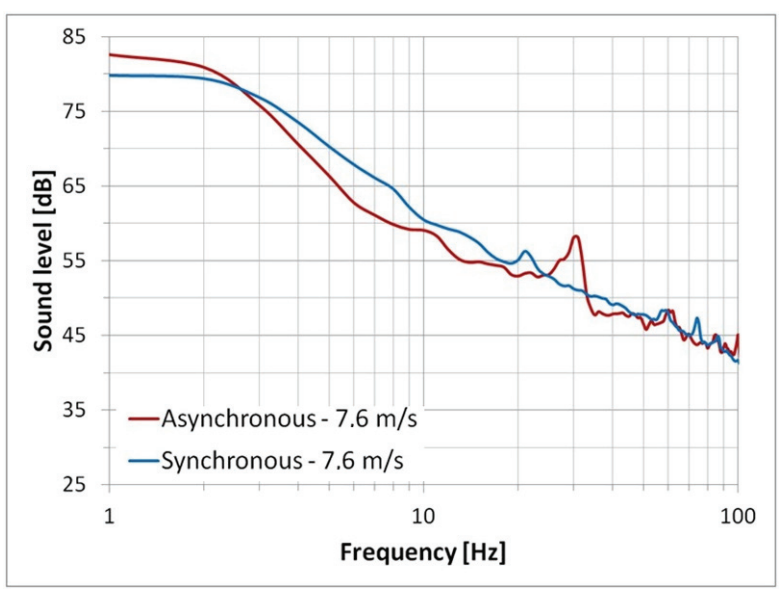

Fig. 7. Frequency spectra of sound pressure levels generated during normal operation of both turbines at wind speed value equal to $7.6 \mathrm{~m} / \mathrm{s}$; Pearson correlation coefficient $r=0.95$.

These frequencies are related to the frequencies of the turbine itself and are associated with rotational speeds of the rotor, generator, and in the case of an asynchronous turbine also the transmission. In order to determine the exact location of emission of measured tonal component it is necessary to conduct more detailed studies associated with continuous monitoring of operating parameters of the constituent elements of the turbine. For asynchronous type turbine the following values were set: $22 \mathrm{~Hz}$ for wind speed equal to $5.4 \mathrm{~m} / \mathrm{s}, 27 \mathrm{~Hz}$ for wind speed equal to $6.3 \mathrm{~m} / \mathrm{s}$ and $31 \mathrm{~Hz}$ for wind speed equal to $7.6 \mathrm{~m} / \mathrm{s}$. In the case of synchronous turbine the frequency equal to $21 \mathrm{~Hz}$ was set for all wind speed values. For these values sound pressure level variations over time were estimated for both considered turbine types separately for each resonance and wind speed. These dependencies are shown in Figs. 7 to 13. For all the datasets the arithmetic mean and standard deviation values were calculated and are summarized in Table 2.

Table 2. Parameters of the infrasound signal gathered by chosen wind speed values and resonant frequencies: average sound pressure level and standard deviation.

\begin{tabular}{|c|c|c|c|c|}
\hline \multirow{2}{*}{ Turbine type } & $\begin{array}{c}\text { Resonant } \\
\text { frequency } \\
\boldsymbol{f}[\mathbf{H z}]\end{array}$ & $\begin{array}{c}\text { Wind } \\
\mathbf{s p e e d} \\
\boldsymbol{v}[\mathbf{m} / \mathbf{s}]\end{array}$ & $\begin{array}{c}\text { Mean } \\
\boldsymbol{L}_{\text {Average }} \\
{[\mathbf{d B}]}\end{array}$ & $\begin{array}{c}\text { Standard } \\
\text { deviation } \\
\boldsymbol{s}[\mathbf{d B}]\end{array}$ \\
\hline \multirow{2}{*}{$\begin{array}{c}\text { asynchronous } \\
\text { turbine }\end{array}$} & 31 & 7.6 & 55.1 & 5.2 \\
\cline { 2 - 5 } & 27 & 6.3 & 55.5 & 3.0 \\
\cline { 2 - 5 } & 22 & 5.4 & 53.2 & 5.6 \\
\hline \multirow{2}{*}{$\begin{array}{c}\text { synchronous } \\
\text { turbine }\end{array}$} & 21 & 7.6 & 56.3 & 1.9 \\
\cline { 2 - 5 } & 21 & 6.3 & 55.9 & 1.8 \\
\cline { 2 - 5 } & 21 & 5.4 & 55.8 & 1.8 \\
\hline
\end{tabular}

On the basis of the calculated standard deviation values the range of variation of the measured signals can be implied. It was stated that turbine design type has an impact on the dynamics of sound level changes in time. The asynchronous type turbine indicates relatively high fluctuations in the value of the measured sound pressure levels; the standard deviation value varies from $3.0 \mathrm{~dB}$ to $5.6 \mathrm{~dB}$ for different wind speeds. In contrast, the synchronous type turbine generates sound, which indicate standard deviations around $1.8 \mathrm{~dB}$ regardless the wind speed value.

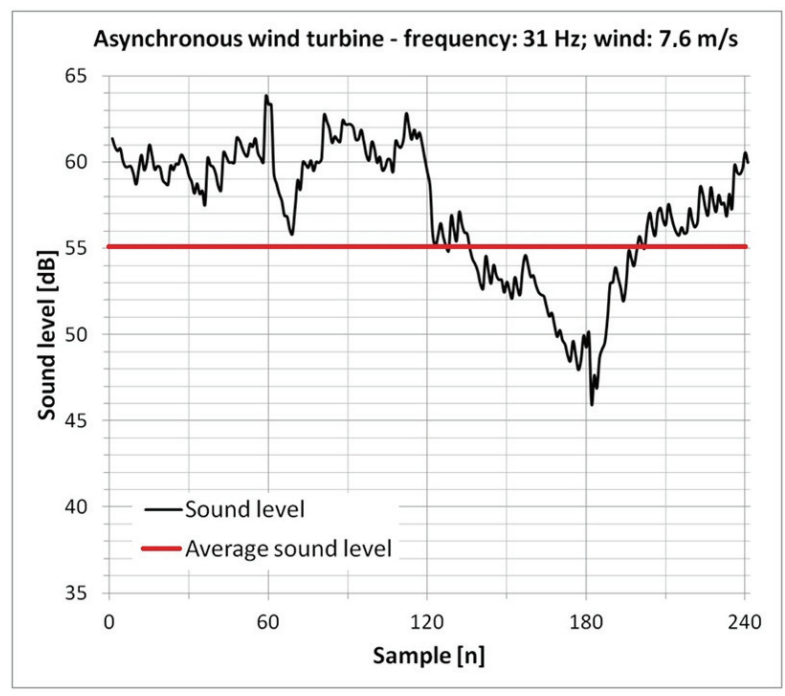

Fig. 8. Variations of sound pressure levels generated by asynchronous type turbine. Depicted data considers resonant frequency value equal to $f=31 \mathrm{~Hz}$ and wind speed value equal to $7.6 \mathrm{~m} / \mathrm{s}$.

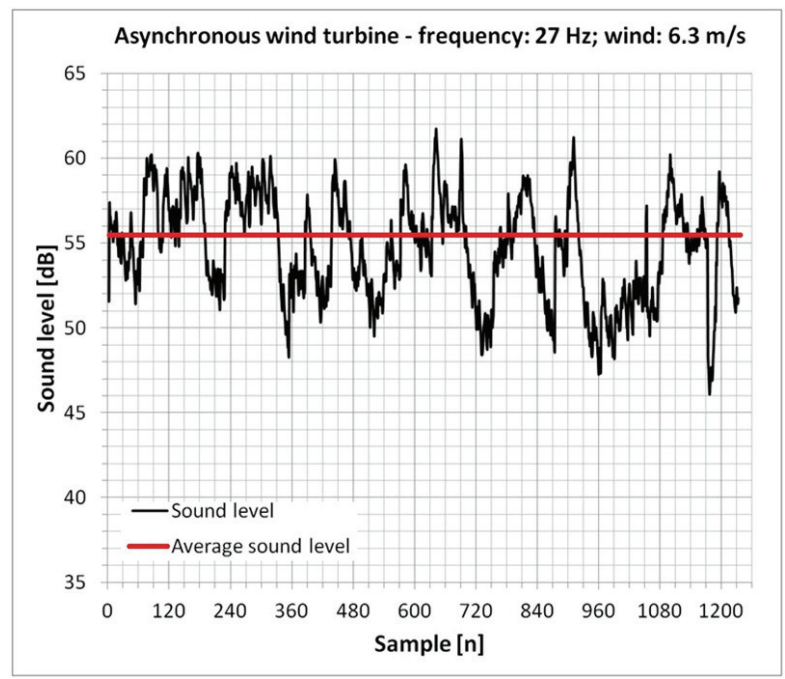

Fig. 9. Variations of sound pressure levels generated by asynchronous type turbine. Depicted data considers resonant frequency value equal to $f=27 \mathrm{~Hz}$ and wind speed value equal to $6.3 \mathrm{~m} / \mathrm{s}$.

When comparing the presented spectra of both turbines (see Figs. 2 and 6), it is to observe that for asynchronous turbine the dynamic operating range of the measured signal is greater. In the spectrum of asynchronous turbine, there are characteristic harmonic components with increased level of sound and also ranges that indicate relatively low levels, as if part of the components was damped. Instead, in the spectrum of synchronous turbine, the dynamic of changes in the measured signal is much lower and any dominant component is relatively difficult to distinguish. Comparing these two spectra, it can also be stated that asynchronous turbine operation is characterized by 
lower sound levels in the infrasound band, as if they were effectively reduced or dumped (at the design stage). The design of asynchronous wind turbine is more modern than the design of synchronous turbine, what may give some explanation for the observed differences. In both cases, the values of measured sound pressure levels are comparable, wherein more recent turbine design has distinctly better acoustic performance with much lower noise levels.

Correlation between individual spectra is very strong, Pearson correlation coefficient $r>0.9$.

Stability analysis of noise level generated as a function of time (see Figs. 8-13).

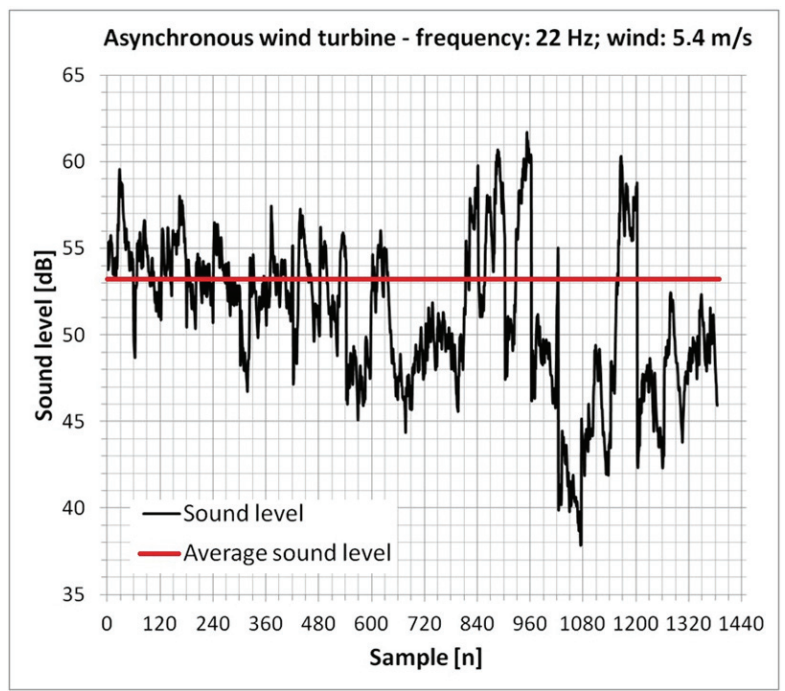

Fig. 10.Variations of sound pressure levels generated by asynchronous type turbine. Depicted data considers resonant frequency value equal to $f=22 \mathrm{~Hz}$ and wind speed value equal to $5.4 \mathrm{~m} / \mathrm{s}$.

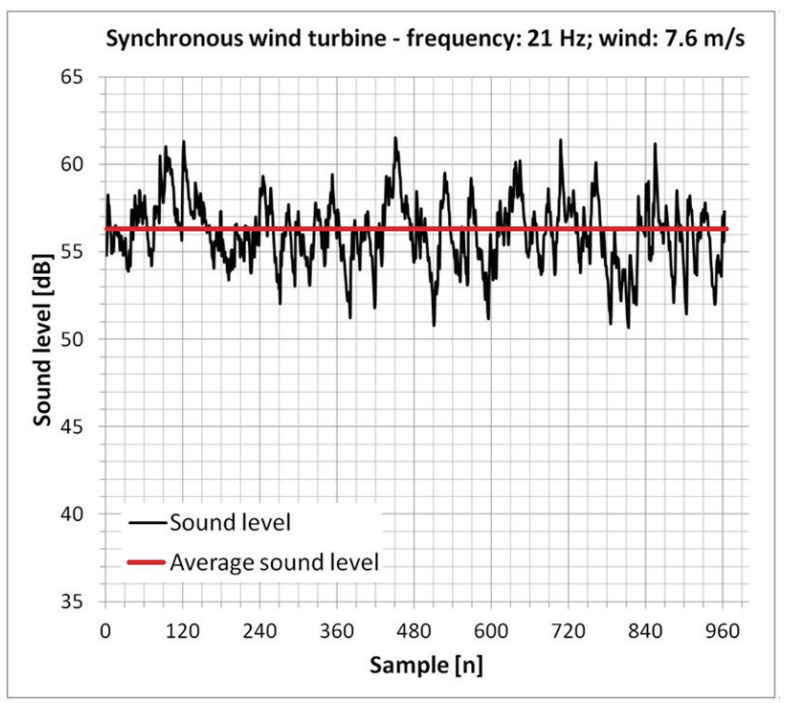

Fig. 11.Variations of sound pressure levels generated by synchronous type turbine. Depicted data considers resonant frequency value equal to $f=21 \mathrm{~Hz}$ and wind speed value equal to $7.6 \mathrm{~m} / \mathrm{s}$.

It is performed for selected resonant frequencies, revealed that although all signals have a similar mean value, the range of changes, expressed as standard deviation of the sample, depends on the design type of electrical power generation system.

Presented figures, which illustrate time changes of the measured values of sound pressure level, clearly indicate that fluctuation range of infrasound noise can go up to approx. $10 \mathrm{~dB}$, which corresponds to changes in the perceived noise level as half shift.

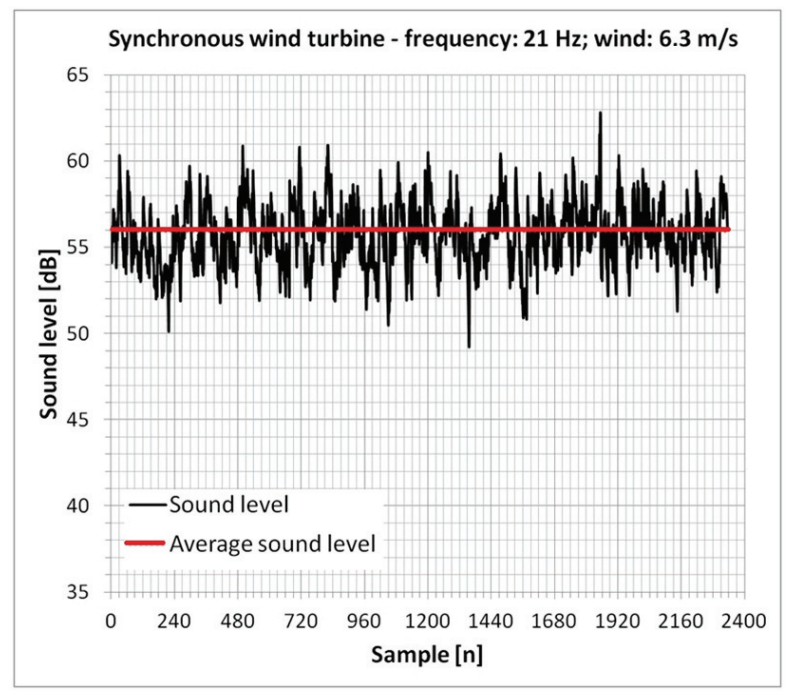

Fig. 12.Variations of sound pressure levels generated by synchronous type turbine. Depicted data considers resonant frequency value equal to $f=21 \mathrm{~Hz}$ and wind speed value equal to $6.3 \mathrm{~m} / \mathrm{s}$.

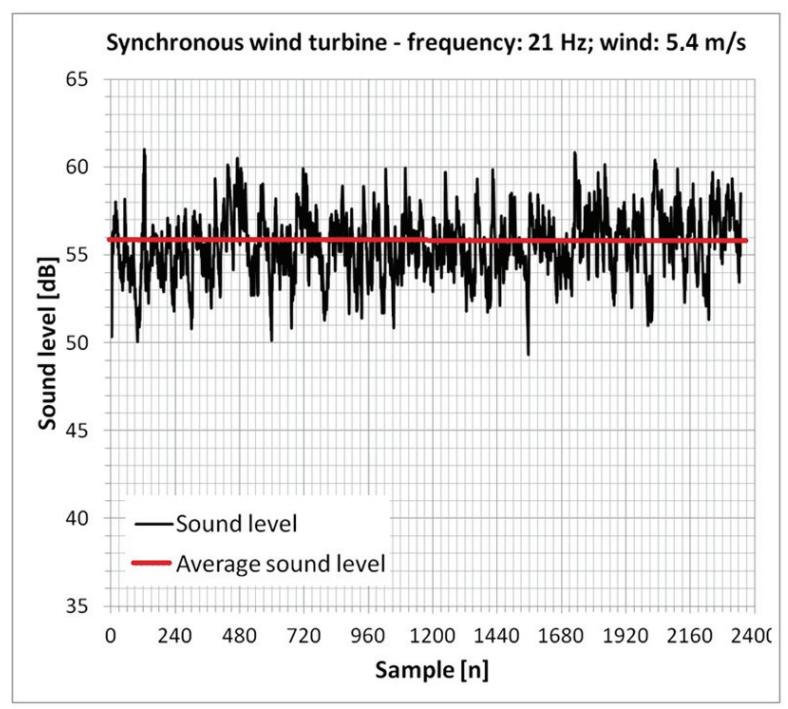

Fig. 13.Variations of sound pressure levels generated by asynchronous type turbine. Depicted data considers resonant frequency value equal to $f=21 \mathrm{~Hz}$ and wind speed value equal to $5.4 \mathrm{~m} / \mathrm{s}$.

\section{Conclusions}

Based on the presented results, it can be stated that operation of wind turbines, regardless of the generator type, causes generation of noise containing infrasound components. However, the registered levels are far 
below the threshold values, above which they would be harmful to humans [3].

Further it was stated that both analyzed turbines indicate relatively linear decrease of the measured sound pressure levels within increasing frequencies. In both cases several harmonic components can be distinguished, for which the sound pressure level is higher than it arises from the trend.

In general it can be stated that the asynchronous type turbine produces lower pressure levels, which are less stable over time, and indicates higher pressure values around the resonant frequencies as compared to the synchronous type turbine. Also it can be stated that the asynchronous type turbine is more influenced by the wind conditions and generates higher pressure values by higher wind speeds then the synchronous type turbine.

Presented results depict a part of research studies related to development and creation of numerical wind turbine model that takes into account the main sources of generation of infrasound, i.e. the mechanical noise coming from the gondola and the aerodynamic noise generated due to operation of rotating blades. In particular, the model will take into account the wind turbine constructional and technical parameters related to type, geometry and size of the turbine, the generated power and the principle of its operation.

\section{Acknowledgment}

The work was co-financed from funds of the National Science Centre (NCS) as part of the OPUS programme, project no.: 2015/17/B/ST8/03371.

\section{References}

1. J.H. Schmidt, M. Klokker, Health Effects Related to Wind Turbine Noise Exposure: A Systematic Review. Tong S., ed. PLoS ONE, 9: dx.doi.org/10.1371/journal.pone.0114183 (2014)

2. G. Bellhose, Low frequency noise and infrasound from wind turbines generators: a literature review Bel Acoustic Consulting, (New Zeland, 2004)

3. D.W.Colby, R. Dobie, G. Leventhall, D.M. Lipscomb, R.J. McCunney, M.T. Seilo, B. Sondergaard, Wind turbine sound and health effects. An Expert Panel Review (2009)

4. D.C. Fernandez Valencia, Infrasound and its effects on humans, Spatial Audio DESC 9137, technical report, University of Sydney (2007)

5. K.L. Hansen, G. Hessler, C.H. Hansen, B. Zajamsek, Prediction of infrasound and low frequency noise propagation for modern wind turbines, a proposed supplement to ISO9613-2, 6th International Conference on Wind Turbine Noise, Glasgow (2015)

6. J. Jakobsen. J. of Low Freq. Noise, Vibr. Act. Contr. 24, 145-155 (2005)

7. M. Kłaciński, T. Wszołek, Arch. Acous. 39, 3-10 (2014)

8. C.Y.H. Qibai, H. Shi, J. Low Freq. Noise, Vibr. and Act. Contr. 23, 71-76 (2004)

9. E. Pedersen, J. Bouma, R. Bakker, F. Van Den Berg, Proceedings of the 7th European Conference on Noise Control, EURO-NOISE, Acoustics, Paris, France, 4049-4054 (2008)

10. A. J. Swerdlow, Health Protect. Agency (2010)

11. H. Tachibana, Proceedings of Inter-noise: 43rd International Congress on Noise Control Engineering, Melbourne, Australia, 1-10 (2014)

12. S. Wegner, R. Bareiss, G. Guidati, Wind Turbine Noise, Springer, Berlin (1996)

13. J. Chilo, T.A. Lindblad, Proc. of 4th IEEE Workshop on Intelligent Data Acquisition and Advanced Computing Systems: Technology and Applications, 35-37 Dortmund (2007)

14. M. Golec, Z. Golec, C. Cempel, Diag.'1 37,115120 (2006)

15. Z. Hameed, Y.S. Hong, Y.M. Cho, S.H. Ahn, C.K. Song, Renewable Sust Energy Rev. 13, 1-39 (2009)

16. F. Toja-Silva, A. Colmenar-Santos, M. CastroGil, Renewable Sustain. Energy Rev. 24, 364-378 (2013)

17. G.P. Van den Berg, Noise notes, J. Low Freq. Noise, Vibr. Act. Contr. 24, 1-23 (2005)

18. B. Yu, Y. Li, X. Wu, Z. Yang, Proceedings of Power Electronics and Machines in Wind Applications, Lincoln, NE, 1-7 (2009)

19. S. Borucki, A. Cichoń, Przegląd Elektrotechniczny 86, 45-47 (2010)

20. A. Cichoń, S. Borucki, T. Boczar, Arch. Acous. 36, 823-830 (2011)

21. H. Majchrzak, A. Cichoń, S. Borucki, Arch. Acous. 42, 29-35 (2017)

22. T. Boczar, T. Malec, D. Wotzka, Acta Phys. Pol. A 122, 850-853 (2012)

23. R. Pierzga, T. Boczar, D. Wotzka, D. Zmarzły, Acta Phys. Pol. A 124, 542-545 (2013)

24. R. Pierzga, T. Boczar, D. Wotzka, Acta Phys. Pol. A 128, 294-298 (2015)

25. M. Szmechta, Acta Phys Pol A 124, 574-577 (2013)

26. D. Wotzka, T. Boczar, T. Malec, R. Pierzga, Acta Phy. Pol. A 124, 595-597 (2013)

27. M. Mahmood, A. Bhutta, N. Hayat, A.U. Ali, R.Sh. Jamil, Z. Hussain, Renewable Sust. Energy Rev. 16, 1926-1939 (2012) 